\title{
SSAT Presidential Address 2014: Here Comes Generation Y!
}

\author{
Robin S. McLeod
}

Received: 7 November 2014 / Accepted: 9 November 2014 / Published online: 13 December 2014

(C) 2014 The Society for Surgery of the Alimentary Tract

"Our youth now love luxury. They have bad manners, contempt for authority; they show disrespect for their elders" (www.quoteinvestigator.com). Does that sound like one of your senior colleagues complaining about the current residents whom he believes are slackards and do not work as hard as he did as a resident? While that quote has been attributed to Socrates and Plato, in fact, it was written by Kenneth John Freeman in 1907 as part of his Cambridge dissertation. The quote highlights the fact that thinking the next generation is lazy, ill mannered, and generally not as good as the previous generation is not new. In fact, it is a recurring view with each generation believing that the next generation is more privileged than the one before.

The term generation is defined as a group of people whose characteristics were shaped and defined by the societal events that occurred during their formative years. While one has to be careful not to stereotype individuals, individuals who are part of a generation often share similar characteristics and values. The most recent generation to enter the work force includes individuals who were born between 1982 and 2002 and is termed "Generation Y" or the "Millenials." In this talk, I would like to discuss what characterizes this generation and the potential impact they will have on society as whole, the workplace, and health care in particular. In addition, I will discuss how we as surgeons and educators as well as the SSAT need to understand this generation in order to accommodate their needs and values since they are the largest demographic group since the Baby Boomers and soon will be our

R. S. McLeod

Department of Surgery, University of Toronto, Toronto, Canada

R. S. McLeod

Mount Sinai Hospital, Toronto, Canada

R. S. McLeod $(\bowtie)$

Cancer Care Ontario, 16th Floor, 620 University Avenue, Toronto, ON, Canada

e-mail: robin.mcleod@cancercare.on.ca

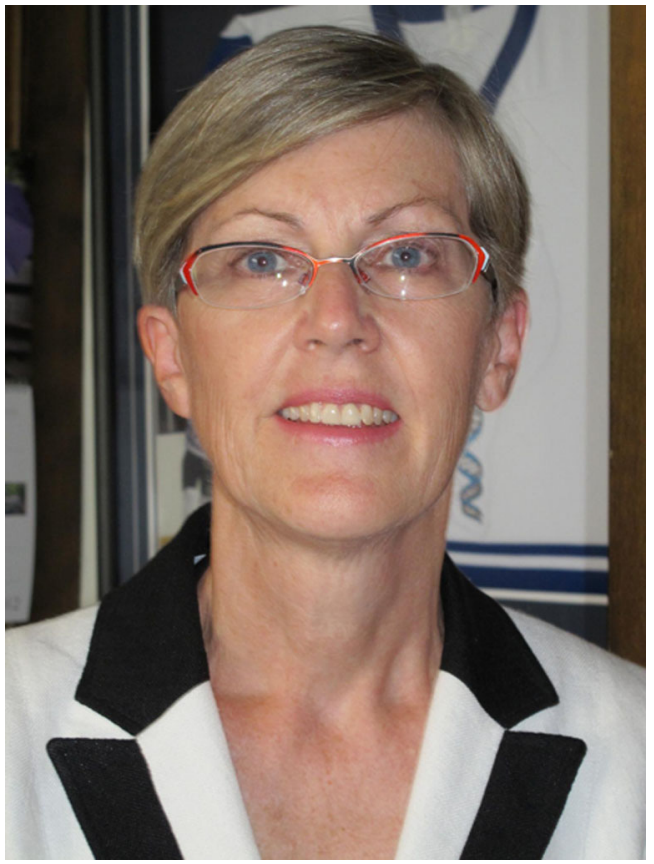

Dr. Robin S. McLeod

successors. This topic seems particularly relevant now as medical and surgical education and health care delivery are undergoing fundamental changes.

\section{Recent Generations}

The most recent generations have been termed the Silent Generation, the Baby Boomers, Generation X, and Generation Y. Members of the Silent Generation were born during the Great Depression and the Second World War (approximately between 1925 and 1944) and thus lived through turbulent times. They have been characterized as having traditional values and are very respectful of authority. They prize security and wealth. In later years, they 
experienced the increased prosperity and security of the $1950 \mathrm{~s}$ and 1960s. They married early and were relaxed parents. They were the first generation where divorce was common. Finally, except during the war, women were generally stay-at-home mothers and not part of the work force.

The Baby Boomers include individuals born between 1945 and 1962. They have been described as being optimistic, rebellious, ambitious, and hard working. Their lives were influenced by more relaxed parenting and the prosperity of the 1950s. They grew up in a time when government provided subsidized housing and education and life was good! As well, technology and innovation were expanding and incredible world events such as the Moon landing influenced their lives. Thus, they believe that anything is possible. During their coming-of-age years, they rejected traditional values. Women were liberated with the introduction of birth control and joined the workforce and demanded acknowledgement. In older years, they have prized youth, good health, and personal material wealth. As well, they continue to have a "live to work" attitude.

Generation $\mathrm{X}$ is described as being fun loving, self reliant, troubled, and cynical. Individuals in this demographic group were born between 1963 and 1982. Their parents were "underprotective" because many were brought up by single parents because of the increasing rate of divorce or parents who both worked. Thus, they have been dubbed the "latch key kids." Their generation was the first to believe that they should work to live, not live to work. They tend to be cynical due to world events such as Watergate and Chernobyl that occurred during their formative years and led to a loss of trust in government and big organizations.

The term Generation Y was first used in an Ad Age Editorial in 1993. Other terms used are Millenials, Generation We/Me, the Global Generation, Generation Next, and the Echo Boomers - the latter because most are the offspring of the Baby Boomers. They are the largest demographic group since the Baby Boomers. There are approximately 80 million individuals who belong to Generation $\mathrm{Y}$ in the USA. It is predicted that because of their size, Generation $Y$ will have an impact on all aspects of our lives including social norms, work, pleasure, and politics. It is estimated that they will account for $50 \%$ of the workforce in 2020.

Perhaps, the biggest influence that has differentiated Generation $Y$ from preceding generations is technology. They are the first generation to grow up with cellphones, computers, iPods, and iPads. They are avid users of the internet. It is their primary source for information, and they use it to share information about themselves and converse with friends, family, and employers alike. They connect on social media such as Intragram at all times of the day and night! Generation Y has also been nurtured, pampered, and programmed by their helicopter parents who have ensured that they have attended the best schools and have been given the best opportunities. They have been told they are special and they can achieve anything.
They have been rewarded not only for excellence but also for participation. And, they have come to believe that they should be rewarded for what they do. Their lives have also been changed by major world events. They have lived in the post 9/11 world. The greatest economic recession since the Great Depression occurred just as some of them were entering the work force. Global warming and other environmental concerns add to their daily pressures and worries.

In an article written in 2008, Generation Y was described as having a number of negative traits including a sense of entitlement, a belief they are special, a lack of loyalty in the workplace, a need for recognition and appreciation even if work is suboptimal, and friends and family are more important than work. ${ }^{1}$ Since many of you in the audience are from the Baby Boomer Generation, I will ask you to reflect on what our parents and teachers may have thought of us as our generation was reaching the age of majority. Remember, we were the marijuana-smoking hippies with long hair and beads who questioned authority, staged sit-ins at our universities, and generally protested all that our parents had worked for. Who would have thought then that the Baby Boomers would turn out to be a conservative generation who value material wealth and live to work? It points out that we should not be too quick to judge the new generation. They may have different values and traits but they are neither better nor worse than those of the preceding generations.

There is also another, more positive, view of Generation $\mathrm{Y}$. Individuals in Generation $Y$ are the most well educated, diverse, and inclusive generation. They have been described as optimistic team players. They do have high expectations because they have been told by their doting parents throughout their lives that they are special and they can accomplish great things. Millenials have liberal views on social and cultural issues such as same sex marriage and diversity. It is predicted that they will be civic-minded with a sense of community, locally and globally. Generally, most want to make a difference in both their work and life. This is exemplified by the amazing work that Craig Kielburger, who gave the Cameron Oration, and his brother, Marc, are doing through their "Free the Children" and "Me to We" initiatives (www.freethechildren.com).

Not surprisingly, technology is a big part of the lives of Generation Y. Junco and Mastrodicasa surveyed 7700 individuals and found that $97 \%$ owned a computer, $94 \%$ owned a cell phone, $76 \%$ used instant messaging, $92 \%$ multitasked while instant messaging, and $34 \%$ said their primary source for news was the internet. ${ }^{2}$ Furthermore, another study found that students who used social media and decided to quit showed the same signs of withdrawal as drug addicts in withdrawal. ${ }^{3}$

Generation Y has also been called the Peter Pan or Boomerang Generation because already, there is evidence of a delay in rites of passage. It is estimated that currently, $12 \%$ of their generation who are less than 35 years live with their parents. In part, this may be related to the high cost of housing 
but it may also be related to their relatively affluent parents being happy to continue supporting them. There also may be more sinister reasons for this delay. Many have a high student debt load because of the high cost of secondary education and a gloomy outlook on their earning potential. Following the recession in 2008, youth unemployment in Europe reached $20-35 \%$ and in the USA, one in two college graduates in 2012 were unemployed. Generation Y suffered the biggest losses in the recession and has benefited least from the economic recovery. There are doubts that they will ever be able to recover lost income. Aside from the likes of Mark Zukerberg of Facebook fame, this generation may be the first generation to not do better than their parents. All of these factors may also make Generation Y share the same concerns of those who lived during the Great Depression, and in particular, there are signs that saving is important to them.

\section{Generation Y in the Workplace}

Generally, Millenials want a job where they can make a difference and where they can have a say in what they work on. They have been criticized for not working hard and wanting a worklife balance. However, it may be more correct to say that they prefer a flexible or blended work life. Baby Boomers have tended to separate their work and private lives. They arrive punctually at 9 AM but also expect to leave punctually at $5 \mathrm{PM}$, and then they are "off" and not to be disturbed. Millenials, on the other hand, are for the most part used to and perhaps prefer working anywhere, anytime, because of their use of technology. So, the boss calling them on Saturday is not discouraged. On the other hand, a personal commitment during the work day may take precedence over work. Thus, they want flexibility in all aspects of work. Additionally, they want to be able to take extended leaves so they can climb Mount Kilamanjaro or build a water system in a village in Africa.

Their upbringing has led them to prefer working in teams and have input into their work assignments. A hierarchial management style runs counter to their experience. At work, they want to have mentoring from managers and receive frequent feedback as well as support - a carryover from their nurturing parents. An interesting study was done by Pricewaterhouse Coopers (PwC) to learn more about their employees. ${ }^{4}$ In particular, they wanted to understand the values of Generation Y so if necessary, they could adapt their work culture to increase retention because they saw Generation $\mathrm{Y}$ as their new workforce. The company surveyed approximately 70,000 employees across the world in 2013. The results of this study disproved some of the stereotypes. In particular, they found that Generation $\mathrm{Y}$ is committed to working hard and work-life balance is not their highest priority. As well, electronic forms of communication are not always preferred. Similar to other generations, they do not expect companies to meet all of their expectations but they do expect to change jobs frequently throughout their careers.

What will the workforce look like? By 2028, all Baby Boomers will be retired and it is predicted that $75 \%$ of the workforce will be composed of Millenials. More women will be in leadership roles. Currently, $60 \%$ of university graduates are females and $25 \%$ of all individuals taking a MBA are female. Hierarchial leadership will be passé and instead there will be a flatter management style. There will be more people working outside of the office "telecommuting," leading to fewer work spaces and increased "hotelling." Blending or flexible hours will be the norm. This will occur in part because there will be more women in the workforce and more twoincome families. They will have increased responsibility for their children as well as their aging parents. This may be especially true since this generation is delaying having children and their parents are living longer. Finally, there will be changes in how we do business due to technology. In-person meetings will decrease as will emails. Instead, social media will be preferred for conversations and for hashing out ideas because it is quicker and more inclusive.

\section{Generation Y Effect on Health Care}

Already, we are seeing changes in work hours in health care because of resident work restrictions. As well, a 2010 survey found that $13 \%$ of males and $36 \%$ of female physicians were working part time. ${ }^{5}$ Other predicted changes include elimination of solo practices, and instead, Generation Y will be comprised of salaried employees working in teams. They will want to be paid on a "pay for value rather than a pay for volume" reimbursement model. While this may have the greatest impact on primary care, it will affect the surgical workforce as well. The general surgeon who is available 24/ 7 may be replaced by individuals who prefer shift work, parttime work, or job sharing. Furthermore, this is a genderneutral issue.

Technology will change the usual patient-doctor relationship and virtual care may become part of the routine. The stethoscope as we know it will be hung up and instead our smart phone will be our new technology. Already, patients can measure their glucose on their smart phone, see the results, and transmit them to their doctor. Work is also being done so heart disease can be managed digitally. At the University of Toronto, one of our plastic surgeons, Dr. John Semple, is performing breast reconstructions using TRAM flaps, discharging patients the same day, and following them daily by having the patients send him photos and symptoms via their smart phones.

What about patient expectations and the effect on care? Using technology, Generation Y will seek out health-related information and be knowledgeable consumers in the same 
way they use their smart phones to find addresses or good restaurants. They will expect that their concerns and preferences will be listened to by health care providers and feel it is their right to have access to the best care. They will expect person-centered care meaning they will want to fully participate in their care including shared decision making and having outcomes which are patient-oriented. They will take more responsibility for their health care. With the implementation of electronic medical records, patients will want and have access to all of their medical information and will share in the responsibility of ensuring that tests are booked and results acted upon.

\section{Effects on Medical Education}

The same themes are consistently seen: Generation Y prefers structured learning and working in teams. ${ }^{6}$ While they are savvy gatherers of information, they tend to lack the skills on how to synthesize, apply, analyze, and interpret data. In other words, they are retrievers and regurgitators of information but need to be taught how to be critical thinkers. They require assistance in understanding what information is important and relevant. Technology is again central to their learning. As an example "Surgery 101" was started by a surgeon, Dr. Jonathan White, at the University of Alberta (www.surgery101.org). He started doing Podcasts on various topics to orient $\mathrm{U}$ of A medical students to surgery. They cover various topics. They soon "went viral" and are being used in countries such as Germany, Brazil, and Romania and have had over one million downloads.

What about residency training? Eckleberry-Hunt and Tucciarone wrote a very thoughtful article which focused on interactive teaching with technology, professionalism, mentoring, and communication and feedback. ${ }^{7}$ They introduced the topic with a vignette of a resident who was thought by staff to be lazy and not engaged whereas the resident gave reasons why he felt it was not possible for him to provide continuity of care. They go on to discuss the differences in perception and how to address the issues.

As with medical student teaching, they acknowledge that Generation Y does not want to sit in lectures and be taught passively. Rather, they want to use technology, have hands on teaching, and prefer group projects where they can work together. On the other hand, they pointed out that residents need to be made aware of when "multitasking with technology" is appropriate and inappropriate. They also point out that debates over professionalism are not unique with older generations feeling that the new generation does not work as hard as they have. They recommend that these issues should be addressed and what is appropriate and inappropriate behavior should be clearly delineated. They also recommend that faculty should not tell residents that their behavior is unprofessional but instead site what specific behavior is not professional. In these discussions, it might be worthwhile to discuss the values that Baby Boomers and Generation X have because just as the older generation has difficulty understanding the values of Generation Y, Generation Y may have a lack of understanding of the values of the older generations.

Mentoring is important to Generation Y residents. It is important that have approachable and supportive faculty because Generation $Y$ wants to know what they are doing right and wrong. They may have difficulty handling negative feedback and learning from their mistakes because they have throughout their lives been told they are perfect. However, they need to learn accountability, responsibility, and independence. Feedback should be given immediately, it should be clear and simple, and assistance may be required to develop a plan to address the concern.

\section{Impact of Generation Y on the SSAT}

The membership of the SSAT is aging and even the Baby Boomers will retire at some time! Thus, to ensure that our society remains viable and relevant, it is important that we are flexible, adaptable, and ready to make changes so our society is attractive to the new generation.

DDW is our major educational event. Large CME events have been the most important source of new knowledge and keeping abreast of new innovations for current surgeons. However, it is already apparent that the internet is the major source of information for Generation Y. As Dr. Marlene Pearce mused in her blog, You can Tell You are a Generation Y Doctor if "you consult the twittersphere, not the library, to find out the most up to date medical research" and "if the internet goes down, you might not remember how to be a doctor \{because\} you haven't bought any textbooks......" This process has already begun. Beginning next year, we will change the format of the Maintenance of Certification Course that is traditionally held on the Saturday of DDW. Instead, we will offer several hands-on courses supplemented by teachings and videos by experts in their fields. We know younger surgeons are interested in new technology and these courses will allow them to learn new techniques.

Generation Y, like previous generations, comes to DDW for other experiences including networking with their peers. We provide these opportunities through our various social events. In addition, our Resident Research Conference and new this year, our Fellowship Job Fair, provide unique opportunities for residents. This year's Fellowship Fair was met with great enthusiasm so our Residents Committee will be looking to grow this event over the next few years.

While our annual meeting has been our signature event, we must consider other educational offerings that can be completed 
on a flexible schedule anytime, anywhere. We also need to consider the platform on which they are provided. Currently, we provide Maintenance of Certification modules and EvidenceBased Guidelines which are available online but we can do more using social media. In doing so, it is also imperative that we involve our younger members in developing these initiatives.

Furthermore, perhaps, we should reconsider the whole concept of how we provide CME or professional development. Miller and colleagues proposed a new model in an article published in $2010 .{ }^{9}$ They advocated for a model where physicians and other health care professionals would receive training within an inter-professional competency-based modular learning system. This would include shared foundational course work embedded in an infrastructure of strong information technology. Educational outcomes would be directly linked to health outcomes. This model should be carefully considered by our leadership. Gone are the days when surgeons are "visiting surgeons" at a hospital. Instead, many now are employees of their health care system. Even if they are not, almost all of us work in multidisciplinary teams composed of physicians from different specialties and a range of allied health personnel which provide complex care to patients. Without all team members working together, we cannot achieve optimal outcomes for which we are accountable. Thus, it makes sense that our professional development should include all members of the multidisciplinary team. This type of training is offered by a few institutions using simulators to teach new techniques. However, this format could be used to improve communication and team building as well as for teaching new procedures.

Lastly, we need to recognize that our membership is more diverse than in previous times. More females are entering our specialty. We are more racially diverse. Thus, their expectations may differ from those of previous generations. Recognizing these changes, our leadership has already made changes. Our members can now self-nominate themselves to sit on committees. Jeff Matthews started a Diversity Task Force during his presidential year to ensure our society is inclusive and that we support diversity in everything we do. Our International Relations Committee is developing partnerships with similar societies in other countries to increase SSAT's global impact. We also have a new "Giving Back committee" which will be of particular interest to Millenials and of course make our society more socially responsible.

In summing up, I want to thank the membership for giving me the honor of serving as President this past year. I have appreciated this opportunity and while I believe that there will be changes to all aspects of our profession and our society, as Generation Y comes of age, I also believe that the SSAT is already adapting and will remain strong and relevant as Generation Y is handed the torch!

Thank you and please enjoy the next few days at DDWremember CHILLAX, because YOLO!

\section{References}

1. Piper LE: The Generation-Y Workforce in Health Care. The New Challenge for Leadership Health Care Manager 2008; 27:98-103

2. Junco R, Mastrodicasa J (2007): Connecting to the Net. Generation: What Higher Education Professionals Need to Know about Today's Students. National Association of Student Personnel Administrators. ISBN 0-931654-48-3

3. Cabral J: Is Generation Y addicted to Social Media. The Elton Journal of Undergraduate Research in Communication 2010 2(1):5-13

4. PWC's NextGen: A Global Generational Study. Evolving talent strategy to match the new workforce reality. Summary and compendium of findings. www.pwc.com

5. Pearl, Robert: How will Boomer, Gen-X, Millenial Doctors Respond to Health Care Changes? Ww.forbes.com/sites/robertpear/2014/04/10/ how will boomer, gen-x, millennial doctors respond to health care changes?

6. Twenge JM: Generational changes and their impact in the classroom: teaching Generation ME. Medical Education 2009; 43:398-405

7. Eckleberry-Hunt J, Tucciarone. The Challenges and Opportunities of Teaching "Generation Y". J Grad Med Educ 2011; 3:458-461

8. Dr. Marlene Pearce, Australian General Practitioner Blogger. "This is How You Know You're a Generation Y Doctor" posted 09302013.

9. Miller B, Moore D, Stead WW et al.: Beyond Flexner: a new model for continuous learning in the health professions. Acad Med 2010; 85: 266-272 